\title{
Experiência da Maternidade no Contexto do HIV/Aids aos Três Meses de Vida do Bebê ${ }^{1}$
}

\author{
Tonantzin Ribeiro Gonçalves ${ }^{2}$ \\ Cesar Augusto Piccinini \\ Universidade Federal do Rio Grande do Sul
}

\begin{abstract}
RESUMO - O estudo investigou a experiência da maternidade em portadoras do HIV/Aids aos três meses de vida do filho/a. Participaram seis mães (19 a 30 anos), de nível sócio-econômico baixo, três das quais já eram portadoras da doença quando engravidaram, enquanto as demais souberam no parto. As mães foram entrevistadas e suas respostas foram examinadas por meio de uma análise de conteúdo qualitativa baseada em quatro eixos teóricos: vida-crescimento, relacionar-se primário, matriz de apoio e reorganização da identidade. Os resultados mostraram que as mães tinham muitas preocupações com a possibilidade de infecção do filho/a e com a saúde do bebê, além de sentimentos de incerteza quanto ao futuro, culpa e medo do preconceito. Esses temores pareciam mais intensos para as mães que tiveram seu diagnóstico no parto. O estigma do HIV/ Aids, conflitos familiares, dificuldades com o diagnóstico e o tratamento, além de restrições sócio-econômicas e em sua rede de apoio exigiam grande esforço emocional dessas mulheres, sugerindo a necessidade de intervenções psicossociais visando à adesão ao tratamento, à qualidade de vida e ao desenvolvimento do bebê.
\end{abstract}

Palavras-chave: HIV/Aids; maternidade; família.

\section{Motherhood Experience in the Context of HIV/Aids in the Third-Month-Baby}

\begin{abstract}
This study investigated motherhood experience in HIV-positive women on the third-month-baby. Six mothers, aged from 19 to 30, from low socioeconomic level took part in this study. Three of these mothers got pregnant knowing that they were infected, while the others were informed during or soon after delivery. The mothers were interviewed and their accounts were examined by means of a qualitative content analysis based on four themes: life-growth, primary relatedness, support matrix, and identity reorganization. The results showed that mothers were worried about having infected their babies and about his/her health. They reported also uncertainty feelings concerning to the future, guilt, and fear of discrimination. These fears seemed more intense for the three mothers who had their diagnosis during or soon after delivery. Issues such as HIV/Aids-related stigma, family conflicts, difficulties in assimilating the diagnosis and the treatment, socioeconomic difficulties and lack of support required large emotional strength from these women. The need for psychological support and psychosocial intervention with these mothers is discussed. This could contribute for their treatment adherence, their quality of life, and the development of their children.
\end{abstract}

Keywords: HIV/Aids; motherhood; family.

A epidemia de HIV/Aids (Human Immunodeficiency Virus/Acquired Immunodeficiency Syndrome) tem revelado um número crescente de mulheres infectadas em idade reprodutiva no mundo todo, despertando preocupação com as taxas de transmissão materno-infantil do vírus (Programa Conjunto de las Naciones Unidas sobre VIH/SIDA, 2006; Szwarcwald \& Castilho, 2000). No Brasil, o Ministério da Saúde concentra seus esforços na aplicação do protocolo de profilaxia da transmissão vertical, ampliando a testagem anti-HIV no pré-natal e no pré-parto, bem como priorizando o atendimento de gestantes (Ministério da Saúde, 2006a). Essas medidas contribuíram para diminuir as taxas de transmissão

1 Este artigo é baseado em parte da dissertação de mestrado de Tonantzin Ribeiro Gonçalves, realizada e apresentada no Curso de Pós-Graduação em Psicologia da Universidade Federal do Rio Grande do Sul sob a orientação de Cesar Augusto Piccinini.

2 Endereço: Instituto de Psicologia, UFRGS, Rua Ramiro Barcelos, 2600/111. Porto Alegre, RS. CEP 90035-006. E-mail: tonanrib@yahoo.com.br. vertical do vírus (Serruya, Cecatti \& Lago, 2004; Souza Jr., Szwarcwald, Barbosa, Carvalho \& Castilho, 2004). No entanto, há ainda muitas carências no sistema de saúde brasileiro em realizar exames anti-HIV no pré-natal (Serruya $\&$ cols., 2004) e, muitas mães ainda não fazem esse exame e/ou qualquer acompanhamento pré-natal (Szwarcwald \& Souza Jr., 2006). Entre parturientes, a prevalência do HIV/ Aids tem se situado em torno de $0,4 \%$, sendo que mais da metade delas desconhece o diagnóstico no momento do parto (Lemos, Gurgel \& Dal Fabbro, 2005).

A prevenção da transmissão vertical é realizada por meio de vários procedimentos que incluem a realização de acompanhamento pré-natal regular, administração de anti-retrovirais (ARVs), exames de contagem de linfócitos TCD4 e carga viral, e cuidados específicos quanto ao parto (Ministério da Saúde, 2006b). Caso a mulher não tenha realizado o anti-HIV na gestação ou não tenha essa informação, realiza-se o teste rápido na admissão na maternidade e, quando positivo, a profilaxia se inicia imediatamente. $\mathrm{O}$ 
bebê deve receber o xarope de AZT nas primeiras 2 horas de vida e até a sexta semana de vida, além de um remédio para prevenir pneumonia. A amamentação pelo leite materno é desaconselhada e a mãe, em geral, recebe remédios para a supressão da lactação. A taxa de transmissão maternoinfantil do HIV/Aids, sem qualquer intervenção, é de aproximadamente $25 \%$ (Connor \& cols., 1994). Conforme dados do Ministério da Saúde (2006b), há uma redução da transmissão vertical para níveis entre 0 e $2 \%$, com a realização de todos estes procedimentos.

Os medicamentos anti-retrovirais, introduzidos nos anos 90, melhoraram drasticamente a expectativa e a qualidade de vida dos portadores do HIV/Aids, possibilitando um planejamento de vida que pode incluir o desejo por ter filhos (Paiva, Lima, Santos, Ventura-Filipe \& Segurado, 2002). Neste sentido, estudos têm indicado que a maternidade pode redimensionar positivamente a vida das portadoras do HIV/ Aids (Antle \& cols., 2001; Nelms, 2005; Tompkins, Henker, Whalen, Axelrod \& Comer, 1999). Por outro lado, a maternidade nesse contexto pode trazer preocupações e sobrecargas psicológicas relacionadas ao enfrentamento do diagnóstico, do status de saúde e do estigma do HIV/Aids, a revelação ou não da doença para a família e a incerteza quanto ao futuro (Ingram \& Hutchinson, 2000; Knauth, 2001; Nelms, 2005; Sandelowski \& Barroso, 2003).

A maternidade, por si só, envolve um intenso trabalho psicológico da mãe desde a gravidez e especialmente ao longo dos primeiros meses do bebê. A mãe precisa elaborar seus sentimentos em relação à gravidez e ao filho, buscando adaptar-se frente a esse papel e às mudanças na família (Brazelton \& Cramer, 1992; Szejer \& Stewart, 1997). Stern (1997) entende que, nesse período de transição para a maternidade e até o primeiro ano do bebê, a mãe encontra-se em um funcionamento psíquico particular que revela preocupações e sentimentos voltados para quatro temáticas específicas: vida-crescimento, relacionar-se primário, matriz de apoio e reorganização da identidade. Tendo em vista que essas temáticas serão utilizadas nas análises dos dados do presente estudo, descreve-se, a seguir, cada uma delas com mais detalhes. O tema da vidacrescimento refere-se às preocupações da mãe, logo após o nascimento do bebê, com a sua capacidade para mantê-lo vivo e promover o seu desenvolvimento físico, incluindo temores relativos à morte do bebê e à sua inadequação quanto aos cuidados (Stern, 1997). Já o relacionar-se primário compreende a formação dos laços de apego, segurança e afeição do bebê com a mãe, os quais promovem o seu desenvolvimento sócio-emocional. Assim, os conteúdos mentais e preocupações da mãe envolvem a sua capacidade de amar e compreender o bebê, de desenvolver sensibilidade suficiente para atender o filho e de criar com ele uma relação recíproca e espontânea de afeto. A matriz de apoio, por sua vez, refere-se à necessidade da mãe de criar, permitir, aceitar e regular uma rede de apoio protetora e de suporte instrutivo e psicológico para que possa dedicar-se ao bebê, mantendo-o física e emocionalmente. Por fim, o tema da reorganização da identidade diz respeito à necessidade da mãe de alterar investimentos emocionais e atividades devido ao nascimento do filho, para desempenhar a função materna.
Desse modo, a complexidade da maternidade pode exacerbar-se frente ao contexto de infecção pelo HIV/Aids. Essa situação pode trazer importante impacto para a experiência da maternidade, especialmente quando essa se soma à condição de vulnerabilidade social e psicológica em que muitas mães portadoras do HIV/Aids encontram-se (Bennetts \& cols., 1999; Ethier \& cols., 2002; Lindau \& cols., 2006; Santos \& cols., 2002; Vermelho, Barbosa, \& Nogueira, 1999). Entretanto, nessa situação, comumente as atenções de saúde concentram-se na prevenção da transmissão vertical. Muitas mulheres recebem o diagnóstico durante uma gestação, quando precisam realizar vários procedimentos em meio a fortes sentimentos de culpa e medo relacionados à possibilidade de infectar o filho (Carvalho \& Piccinini, 2006; Coelho \& Motta; 2005; D'Auria, Christian \& Miles, 2006; Kwalombota, 2002; Moura \& Praça, 2006). Assim, o período após o nascimento é permeado pela incerteza quanto ao diagnóstico do bebê e pelas dificuldades das mães em manter o próprio tratamento (Ickovics \& cols., 2002).

Em relação à maternidade no contexto do HIV/Aids, somente um dos estudos revisados focalizou o período inicial da criança. Além disso, a maior parte das pesquisas envolvendo mães de filhos mais velhos foi realizada antes da popularização dos ARVs (D’Auria \& cols., 2006; Ingram \& Hutchinson, 1999a, 1999b, 2000; Tompkins \& cols., 1999; Van Loon, 2000). A influência da soropositividade e da profilaxia para a prevenção da transmissão vertical sobre aspectos psicológicos implicados na gestação, no parto, no não-aleitamento materno e no puerpério de mães portadoras do HIV/Aids são pontos ainda pouco explorados. Quanto às mães que se descobrem portadoras do HIV/Aids durante o parto não foram encontrados estudos sobre aspectos psicológicos do diagnóstico nessa situação e seu impacto sobre a maternidade. Considerando essas lacunas, o presente estudo buscou compreender a experiência da maternidade no contexto do HIV/Aids aos três meses de vida do bebê. Em particular, investigou-se a maternidade entre mães que já se sabiam portadoras do HIV/Aids e outras que souberam durante o parto.

\section{Método}

\section{Participantes}

Participaram deste estudo seis mães portadoras do HIV/ Aids, com idades entre 19 e 30 anos, que tinham bebês entre 3 e 4 meses de idade, residentes na região da Grande Porto Alegre. Três dessas mães engravidaram sabendo que já eram portadoras da doença há três ou mais anos, enquanto as demais ficaram sabendo apenas na hora do parto ou logo após o nascimento do filho/a. As participantes tinham um nível de contagem de linfócitos TCD4 entre 919 e 256 células $/ \mathrm{mm}^{3}$, sendo que nenhuma tinha ou já tinha tido diagnóstico de Aids até o momento das entrevistas. Os bebês não apresentaram malformações ou problemas graves de saúde e todos estavam em acompanhamento pediátrico para crianças expostas ao HIV/Aids, sendo que nenhum tinha apresentado carga viral detectável até a realização das entrevistas. A Tabela 1 apresenta alguns dados sócio-demográficos e sobre o diagnóstico de infecção pelo HIV/Aids das participantes. 
Tabela 1. Dados sócio-demográficos das mães.

\begin{tabular}{|c|c|c|c|c|c|c|}
\hline Caso & Idade & Escolaridade & Ocupação & Estado civil & Filhos & $\begin{array}{c}\text { Tempo de diagnóstico } \\
\text { HIV/Aids }\end{array}$ \\
\hline M1 & 19 & $4^{\mathrm{a}}$ série completa & Do lar & Casada (1 ano) & † 4 meses & 4 meses \\
\hline M2 & 24 & $2^{\circ}$ grau incompleto & Do lar & Casada (3 anos) & \ 5 anos, + 3 meses & 3 meses \\
\hline M3 & 27 & $5^{\mathrm{a}}$ série completa & Do lar & Separada há 2 meses & $\begin{array}{l}\text { } 12 \text { anos, }+5 \text { anos, } \\
\text { } 3 \text { anos, ㅇ } 3 \text { meses }\end{array}$ & 3 meses \\
\hline M4 & 30 & Analfabeta & $\begin{array}{l}\text { Vendedora de } \\
\text { roupas usadas }\end{array}$ & Casada (10 anos) & $\begin{array}{l}\text { o } 15 \text { anos, o } 12 \text { anos, } \\
\text { o } 7 \text { anos, } \delta 3 \text { meses }\end{array}$ & 6 anos \\
\hline M5 & 19 & $6^{\mathrm{a}}$ série incompleta & Do lar & Casada (5 anos) & $\begin{array}{l}\text { } 93 \text { anos, ô } 1 \text { ano, } \\
\text { o } 4 \text { meses }\end{array}$ & 3 anos \\
\hline M6 & 21 & $5^{\mathrm{a}}$ série completa & Do lar & Casada (1 ano) & 3 anos, +9 meses & 3 anos \\
\hline
\end{tabular}

\section{Procedimentos e instrumentos}

As mães foram contatadas durante o acompanhamento pediátrico de seus filhos em uma Unidade de Saúde de referência em HIV/Aids da Grande Porto Alegre. Os profissionais do serviço foram informados sobre o estudo e solicitados a indicar possíveis participantes. Aquelas que concordaram em participar preencheram a Entrevista de dados sócio-demográficos da família, utilizada para identificar dados como idade, escolaridade, situação conjugal e ocupacional, e informações para contato posterior. Depois disso, foi marcado um encontro com cada mãe, quando foi assinado o Termo de Consentimento Livre e Esclarecido. Nessa oportunidade, as mães responderam a Entrevista sobre a experiência da maternidade em situação de infecção pelo HIV e sobre o desenvolvimento do bebê que investigou, de maneira aprofundada, os sentimentos das mães a respeito da maternidade na presença do HIV/Aids, a história da infecção pelo HIV/Aids e suas repercussões para a mãe, a família e o bebê. Essa entrevista continha blocos de perguntas sobre a gestação, o parto, os primeiros dias com o bebê; a reação da família e do companheiro à gravidez e ao nascimento do bebê; a saúde e o acompanhamento médico da criança; as impressões e sentimentos da mãe sobre o desenvolvimento, aspectos do cuidado e comportamentos do filho; preocupações e planos quanto ao futuro; sobre o relacionamento da mãe com a sua família; a participação do pai da criança nos cuidados e como estava a relação da mãe com ele. Além disso, as mães responderam ao Protocolo de avaliação da adesão ao tratamento para HIV/Aids que visou obter dados sobre a forma de transmissão, sobre a saúde e o tratamento médico da mãe e do bebê. Todas as entrevistas eram estruturadas, realizadas de forma semidirigida, numa sala reservada da Unidade de Saúde, sendo gravadas em áudio e, posteriormente, transcritas.
O presente estudo foi aprovado pelo Comitê de Ética da Universidade Federal do Rio Grande do Sul (Proc. ${ }^{\circ}$ 2005/494) e pelo Comitê de Ética em Pesquisa do Hospital de Clínicas de Porto Alegre (Proc. n 2005/601). Todas as mães assinaram um Termo de Consentimento Livre e Esclarecido e lhes foi fornecida uma cópia do documento.

\section{Resultados e Discussão}

Foi realizada uma análise de conteúdo qualitativa (Bardin, 1977; Laville \& Dione, 1999) com base nos quatro eixos temático-interpretativos da constelação da maternidade (Stern, 1997): vida-crescimento, relacionar-se primário, matriz de apoio e reorganização da identidade, descritos anteriormente. A partir da leitura exaustiva das transcrições das entrevistas, buscou-se identificar os relatos das mães que faziam referência a cada um dos eixos temáticos. Ao longo das análises investigaram-se particularidades e semelhanças entre os casos, em especial quanto ao fato de já se saber infectada na gestação ou ter tomado conhecimento só no parto. A seguir, apresenta-se a caracterização de cada tema, ilustrando-os com os relatos das mães em relação à gestação, ao parto, aos primeiros dias com o filho/a e até o terceiro mês de vida ${ }^{3}$. Após a apresentação dos resultados de cada temática busca-se discutir os achados articulando-os à literatura disponível.

3 Na dissertação de mestrado, na qual se baseou este trabalho, são apresentados inúmeros outros exemplos de relatos das mães, que não foram incluídos no presente artigo por falta de espaço. Em função disto, aqui também se buscou editar algumas citações, excluindo partes que não eram fundamentais para o seu entendimento. Salienta-se também que todos os nomes utilizados nas vinhetas são fictícios. 


\section{Vida-crescimento}

Este tema refere-se às preocupações com a competência e condições para assegurar o crescimento físico do bebê (Stern, 1997). As mães do presente estudo relataram vários temores com a saúde e o desenvolvimento do filho/a, desde a gestação e até seus três meses de vida. Em particular para as mães que já tinham conhecimento de sua infecção, a gestação foi vivida com muita ansiedade pelo medo de transmitir o vírus ao filho/a, somando-se a dificuldades financeiras, à medicação e ao pré-natal: "Eu entrei em desespero [quando engravidou], porque eu digo: 'Bah, será que o nenê vai nascer assim, será que ele vai nascer com esse tal de... dessa doença ai'. O que eu não quero pra mim eu não quero pros meus filhos" (M4).

Quanto ao nascimento do filho/a, quatro mães (M1, M2, M3 e M4) relataram ter tido dificuldades para chegar ao hospital e problemas de saúde que precipitaram o parto. Algumas mães (M1, M2, M4, M5, M6) temiam que algo acontecesse ao filho/a durante ou logo após o parto, que ele fosse doente ou frágil e viesse a falecer. Entre as três mães que souberam da doença na maternidade, o desconhecimento do HIV/ Aids, associado a imprevistos, não permitiram a realização completa da profilaxia no parto, o que gerou preocupações intensas após o parto e até a sensação de morte iminente: "Resolveram fazer uma cesárea de urgência Ela nasceu de sete [meses], nasceu com um quilo oitocentos e cinqüenta. Daí eu pensei assim, eu não fiz nenhum tratamento durante a gestação e ainda se eu soubesse. Eu fiquei com medo que ela pegasse também" (M2).

Durante os primeiros dias após o parto, as mães afirmaram temer que o filho/a estivesse infectado pelo HIV/ Aids, em especial, quando esse(a) apresentou problemas de saúde: "Ele já nasceu com o olhinho saindo infecção, uma coisa no olho. Aí ele foi pra casa, um mês ele voltou pra cá e ficou abaixado uma semana aqui. Ele tem bronquiolite também, além da bronquite. Ele ficou abaixado uma semana, ai eu fiquei desesperada" (M4). Essa mesma mãe (M4) preocupava-se porque não tinha como comprar o leite e, na época, desconhecia a gratuidade do fornecimento das latas. Todas as mães expressaram sentimentos de inferioridade e tristeza por não amamentar: "Eu me senti bem inferior às outras pessoas, mas bem triste por não poder dar o peito. Bem triste mesmo. Parece que a gente não tá podendo ajudar o teu filho, sabe" (M2). Mesmo assim, cinco mães (M1, M2, M3, M4, M6) enfatizaram que o desejo de evitar que o filho/a fosse infectado as fazia superar as dificuldades e as próprias crenças em relação à amamentação: "Eu não gostei muito porque eu gosto de dar mamá [no peito], porque a criança não fica doente muito e é bom. Eu sabia que eu não podia dar por causa da doença e eu não dei. Eu pensava que a criança que não mama no peito não se alimenta direito mas ela tá se alimentando bem" (M3).

Aos três meses de vida do filho/a, a principal preocupação das mães relacionava-se ao diagnóstico do filho/a. Quase todas as crianças já haviam realizado exames anti-HIV e, com exceção de duas mães (M2, M5), todas as outras já sabiam o seu resultado. Esses bebês apresentaram carga viral indetectável o que abrandava um pouco os temores das mães, mas não sua ansiedade em saber o diagnóstico definitivo.
Sabendo que isto ainda não era possível, as mães buscavam pensar positivamente e rezavam, recorrendo à fé em Deus e esperando que Ele impedisse a infecção do filho/a: "Eu vou empurrando com a barriga, sempre pedindo a Deus que ela não tem culpa se eu errei, que não passe pra ela se eu ou ele errou. Porque ela é pequenininha, é inocente, não entende quase nada" (M1).

Junto a essas incertezas, as mães temiam que o filho/a contraísse gripes, resfriados e/ou outras doenças, o que fazia com que aumentassem os cuidados com ele/a. As mães procuravam cumprir rigorosamente o acompanhamento pediátrico, a realização de exames e a administração de remédios, assegurandose de que estavam fazendo todo o possível pelo filho/a: "Eu me preocupo de sair com ela no vento, ou de ficar muito tempo no sol, tudo isso me preocupa. De pegar uma gripe, alguma coisa, mesmo eu não sabendo se ela tem o vírus, porque eu vou saber só dia onze agora que eu vou consultar com ela. Mesmo eu não sabendo eu fico. Eu não posso esquecer [de dar o remédio à filha]" (M2). Pelo menos quatro bebês (filhos de M1, M3, M4, M6) apresentaram problemas dermatológicos ou infecções nos brônquios, exigindo internações e cuidados especiais, o que agravava os temores das mães com a saúde do filho/a e com a possibilidade de que ele/a estivesse infectado: "A não ser com o negócio do vírus, como ela tá doentinha, eu fico preocupada. Que nem agora ela tá com bronquiolite, fico preocupada se ela vai ficar de novo, se ela vai baixar hospital. Quando ela começa a tossir, eu fico bem preocupada. Quando ela começa com o nariz..." (M6).

Para as três mães que se sabiam portadoras do HIV/ Aids na gravidez, algumas preocupações com a saúde, com a alimentação e com o desenvolvimento do filho/a pareciam ser, em parte, suavizadas pelo sucesso com a profilaxia da transmissão vertical com um filho/a mais velho: "No hospital já tinham me explicado que era pra tomar o leite em pó e eu já tava acostumada com o primeiro [filho], então eu já tinha experiência” (M6). Essas mães tinham como certo que o filho/a não estava infectado pelo HIV/Aids e não imaginavam um resultado diferente: "Eu não penso nem um minuto nisso aí [infecção do filho] sabe, não tem como eu... Eu tenho que ter fé em Deus e não penso um minuto que ele tenha isso ai" " (M4). Ao mesmo tempo, para as outras três mães o impacto do diagnóstico ainda era muito recente, sendo que lhes faltavam informações mais precisas sobre a doença, sobre como acontecia o diagnóstico do filho/a e sobre os cuidados que deviam ter, como, por exemplo, a administração diferenciada de vacinas: "A única preocupação pra mim agora é as vacinas e eu não sabia que ela tinha que fazer vacinas diferenciadas de outras crianças, eles não me falaram nada disso [se emociona]. Porque até então eu pensava que ela também tinha o vírus que nem eu. Eu sabia que ela fazia exame, mas eu não sabia que ninguém sabia ainda se ela tem ou não o vírus" (M2). Essas mães exprimiram de modo mais claro a possibilidade que o filho/a pudesse estar infectado e, diante disso, acreditavam que assumiriam uma atitude de resignação e dedicação aos cuidados com o filho/a: "[Se for positivo] vai ser a mesma coisa, eu vou continuar cuidando ela, levando no hospital, tudo" (M3).

As mães ainda referiram outros temores não explicitamente relacionados à infecção pelo HIV/Aids, como preocupações com a introdução de novos alimentos, higiene, sono 
e choro do filho/a, e com a falta de condições financeiras. Apesar das suas apreensões, todas as mães referiram algum aspecto positivo em relação ao crescimento e a saúde do seu filho/a como o fato de ter o peso e o tamanho adequados para a idade, estar se alimentando bem e não ter tido doenças sérias. Diante disso, as mães demonstraram sentimentos de satisfação ou alívio: "Ela nasceu bem, não nasceu como eu pensei que ia nascer. Dei graças a Deus que com ela não deu nada e ela foi pra casa comigo" (M5).

Os relatos acima apontam que o HIV/Aids representava para essas mães uma ameaça à sua saúde e à vida do seu filho/a. Nesse cenário, a religiosidade fornecia significados e servia como uma fonte de apoio para lidar com o próprio diagnóstico e com a possível infecção do filho/a, como destacado em outros estudos (Carvalho \& Piccinini, 2006; D'Auria \& cols., 2006). Nesse sentido, o HIV/Aids era considerado por algumas mulheres como um castigo e não como fruto de comportamentos de risco que adotaram. A proibição de amamentar o filho/a no seio foi outro aspecto bastante penoso para essas mães, visto que a amamentação é envolta em crenças, significados e ditames científico-culturais relativos à feminilidade e à boa mãe (Almeida \& Novak, 2004; Moreno \& cols., 2006). Dessa forma, percebeu-se que as preocupações diretamente ligadas ao HIV somavam-se a outras apreensões comuns nos primeiros meses do bebê, contribuindo para que as mães centrassem seus esforços na criança, como encontrado em estudos com mães portadoras do HIV/Aids de filhos mais velhos (D'Auria \& cols., 2006; DeMarco, Lynch \& Board, 2002; Nelms, 2005).

Examinando conjuntamente os relatos das mães que já sabiam da infecção na gestação ou só ficaram sabendo no parto, algumas semelhanças e particularidades ficaram evidentes. Para as mães que já se sabiam portadoras, a preocupação com a transmissão do vírus ao fillho/a já estava presente desde a gravidez, corroborando achados de outros autores (Carvalho \& Piccinini, 2006; Coelho \& Motta, 2005; Moura \& Praça, 2006). As preocupações com a gestação na presença do HIV/Aids juntavam-se a temores com problemas familiares e de saúde e com o pré-natal, os quais também foram relatados pelas mães que ainda não sabiam de sua infecção. O presente estudo, por sua vez, evidenciou que esses temores e sentimentos permaneceram após o nascimento do filho/a e, até mesmo, intensificaramse quando a criança apresentou problemas de saúde mesmo que não relacionados ao HIV/Aids. As experiências anteriores de maternidade na presença do vírus parecem não ter diminuído a ansiedade quanto ao diagnóstico do filho/a, demonstradas por todas as mães.

Após o nascimento do filho/a, as mães que já sabiam de sua doença na gestação demonstraram estar prevenidas quanto ao acompanhamento médico e aos cuidados com o filho/a durante seus primeiros meses. Esse conhecimento parecia amenizar um pouco sua apreensão com a realização das recomendações, porque já tinham essas informações na gravidez e/ou em função do nascimento de outros filhos na presença do HIV/Aids. Por outro lado, as mães que descobriram a infecção na hora do parto precisavam absorver, em um só tempo, o próprio diagnóstico, as repercussões disso nas suas vidas e as informações sobre procedimentos e cuidados com o filho/a.
Frente ao diagnóstico, essas mães referiram sentimentos e reações intensas semelhantes àquelas relatadas na literatura (Ferraz, 1998; Seffner, 2001; Stevens \& Doerr, 1997). Porém, no contexto de nascimento de um filho/a, verificou-se que essas reações dizem respeito também à criança e podem ser bastante traumáticas e marcantes para as mães e para sua relação com o filho/a. Essas mulheres revelaram preocupações que eram, em parte, fruto do desconhecimento sobre o acompanhamento e tratamento dos filhos e, por outra parte, porque entendiam que as chances de não-infecção do filho/a aumentariam se tivessem iniciado a profilaxia na gestação.

\section{Relacionar-se primário}

Esse segundo eixo temático proposto por Stern (1997) diz respeito às preocupações da mãe com o seu envolvimento emocional com o filho/a após o seu nascimento. No presente estudo, todas as mães manifestaram esse tipo de preocupação, embora isso não tenha sido relacionado especificamente à situação de infecção pelo HIV/Aids. Em sua maior parte, as preocupações das mães após o nascimento do filho/a referiam-se a situações de afastamento temporário do filho/a e da necessidade de cuidado por outras pessoas. As mães temiam que algo acontecesse ao filho/a na sua ausência, que ele fosse maltratado ou não recebesse cuidados adequados, referindo sentimentos de angústia e aflição nesses momentos: "Eu saio porque eu tenho que sair, eu tenho que trabalhar, eu tenho que ir à luta. Eu penso assim: Será que vão cuidar que nem eu cuido? Será que vão dar atenção pra ele que nem eu dou? Eu acho que ninguém dá mais atenção do que a mãe. Então eu já saio preocupada" (M4). Algumas mães (M3, M4, M5, M6), mesmo que o filho/a estivesse aos cuidados de uma pessoa em quem confiavam, não se sentiam completamente seguras. Em três casos (M1, M3, M4), essas preocupações envolviam a necessidade de voltar a trabalhar fora de casa.

Duas participantes (M1, M5) preocupavam-se com as conseqüências que as brigas recorrentes do casal poderiam ter para o desenvolvimento emocional do filho/a: "Ass vezes fica difícil, ela pode não tá na volta quando a gente briga mas o estresse fica e dai se eu vou pegar ela, já passa pra ela, ela já começa a chorar. Se ele [o marido] vai pegar ela, ele chega perto, ela começa a chorar" (M1). A única mãe que era primípara (M1) referiu ainda o medo de estar sendo uma mãe inadequada e de que suas escolhas prejudicassem a filha no futuro. Além disso, ela sentia que a relação com a filha era afetada negativamente pela interferência dos familiares do marido.

Todas as mães salientaram aspectos positivos de seu relacionamento inicial com o filho/a. Pelo menos quatro mães (M3, M4, M5, M6) revelaram ter experimentado um forte apego e afeto pelo filho/a já durante a gestação, em especial, depois da percepção dos primeiros movimentos fetais ou da realização de ecografias. A certeza quanto ao sexo do bebê, a ansiedade pelo nascimento do filho/a e a intensidade do primeiro encontro com o filho/a denotavam o vínculo que as mães já mantinham com ele/a: "Eu não via a hora de ganhar ele quando eu tava grávida. Dai quando ele nasceu tinha que ver, ele pra mim e pro pai dele, ele é tudo. Ele nasceu 
bem pequeninho, ele é a coisa mais linda do mundo" (M4). Metade das mães (M3, M5, M6) relatou interagir com o filho/a, conversando e tocando na barriga durante a gravidez. Duas mães (M4, M6) ainda destacaram que os primeiros movimentos e sinais do filho/a facilitaram a aceitação da gravidez, bem como o sentimento de amor por ele/a.

No final do primeiro trimestre de vida do filho/a, as mães demonstraram grande satisfação pelos avanços apresentados pelos filhos no que se referia a sua comunicação e interação com eles. A sensação de estar entendendo as necessidades da criança, de que esta reconhecia a mãe e respondia às suas brincadeiras e conversas foram salientadas por todas participantes: "Eu gosto de conversar com ela, ela faz carinho, ela puxa meus cabelos, ela tenta fazer carinho. Quando eu tô conversando com ela, eu gosto de brincar com ela bastante. Porque ela vai desenvolver melhor. Porque conversando assim ela se desenvolve, ela segue a mamadeira, ela sabe a diferença da mamadeira do leite e a de água" (M1). Para uma das mães, as habilidades demonstradas pelo filho serviam, inclusive, como indícios de que ele era saudável e não estava infectado pelo vírus: "Conversa e trova e diz: 'Abú'. Ele chama o pai dele de bobo: 'Bobu', ele diz pro pai dele. Ele tá a coisa mais linda do mundo, por isso que eu fico pensando, ele não deve ter essa, sabe... essa doença ai porque ele é muito sadio" (M4). De forma geral, as mães consideravam que ser portadora do HIV/Aids não havia influenciado sua relação com o filho durante seus primeiros meses de vida. Uma das mães apontou que o fato de achar que a filha fosse portadora do HIV/Aids a fez pensar que ela precisava de mais carinho, como uma forma de reparar a transmissão da doença, idéia que foi abandonada quando lhe esclareceram que a filha poderia não estar infectada: "Então se ela tem esse virus, ter um cuidado mais especial com ela. Dar mais carinho pra ela, dar mais tudo pra ela. Eu pensei assim: Não, ela é uma pessoa como qualquer outra. Quando eu soube na semana passada que ela poderia não ser portadora, já deu um alivio" (M2).

Contudo, as três mães que receberam o diagnóstico na maternidade destacaram inquietações com a influência que a doença poderia ter na relação com os filhos no futuro e temiam suas reações à notícia. No caso do filho/a ser portador do HIV/Aids, essas mães se preocupavam com o tratamento de saúde e com os cuidados que o filho/a precisaria ter no futuro, com a culpa que sentiriam e com a discriminação: "Se der positivo [o exame] como é que eu vou conversar com ela? Vai chegar uma certa idade dela, se ela tiver o vírus, vai chegar uma certa idade que eu vou ter que explicar pra ela, pra ela se cuidar, o que comer. E dai eu não sei, eu tenho medo da reação dela depois" (M1).

Como pode ser visto nos relatos acima, aos três meses de vida do filho/a, as mães demonstraram um forte envolvimento emocional com o filho/a, o que para quase todas já estava presente desde a gestação. Elas também enfatizaram sua satisfação com a relação que mantinham com o filho/a no momento e afirmavam que ser portadora do HIV/Aids não interferia no vínculo com ele/a. Nesse sentido, evidenciouse que a ameaça do vírus precisava ser posta em segundo plano para assegurar a construção de uma relação de afeto autêntica e espontânea entre mãe e filho/a. As mães evitavam pensamentos negativos relacionados à sua própria infecção e ao risco de tê-la transmitido ao filho/a, o que pode indicar a busca pela proteção da criança (cf. Ingram \& Hutchinson, 1999a; Sandelowski \& Barroso, 2003). As participantes revelaram estar bastante sensíveis às necessidades expressas pelo filho/a, enquanto as suas aquisições e sinais de crescimento pareciam apoiá-las e motivá-las como mães. Outro indício da intensa identificação das mães com o filho/a foram as suas preocupações quanto às situações em que ficavam afastadas dele/a e precisavam deixá-lo com outras pessoas, temores relatados na literatura como característicos desse período (Lopes, Alfaya, Machado \& Piccinini, 2005). Mesmo assim, é possível que a incerteza das mães quanto ao diagnóstico do filho/a e quanto ao seu próprio futuro reforçasse o medo de afastar-se dele/a, ao mesmo tempo em que a interação com ele/a era priorizada.

A comparação dos relatos das mães que já se sabiam portadoras do HIV/Aids e daquelas que souberam no parto, quanto ao relacionar-se primário, revelou mais similaridades do que particularidades. Contudo, somente as mães que tiveram seu diagnóstico mais recentemente relataram temer o preconceito com os filhos e preocupavam-se com os cuidados dele/a, caso fosse portador/a do vírus. Em consonância com os achados de outros pesquisadores, essas mães se preocupavam com a influência que a infecção pelo HIV/Aids poderia ter na sua relação com os filhos no futuro (Antle \& cols., 2001; D'Cruz, 2002; Ingram \& Hutchinson, 1999a, 2000; Van Loon, 2000). Por outro lado, as mães que se sabiam portadoras do HIV/Aids antes da gravidez não relataram tais preocupações. Diante das diferenças parciais entre os relatos das mães do estudo e a literatura destaca-se que as pesquisas citadas foram realizadas antes do advento dos ARVs, os quais melhoraram a qualidade de vida dos portadores do HIV/Aids. Desse modo, é possível que o impacto recente do diagnóstico durante o parto estivesse influenciando as percepções e as expectativas dessas mães quanto ao futuro. Com o tempo e com a aquisição de novas informações, talvez essas mães pudessem elaborar melhor seus sentimentos e opiniões sobre a doença e o tratamento.

\section{Matriz de apoio}

Este terceiro eixo-temático de Stern (1997) refere-se à necessidade das mães de criar, permitir, aceitar e regular uma rede de apoio para cuidar do filho/a física e emocionalmente, e inclui as suas impressões sobre como as pessoas a vêem no papel de mãe. No presente estudo, todas as mães referiram ter recebido ou estar recebendo alguma forma de apoio desde a gestação e até o momento da entrevista, seja do marido, de sua família extensa ou de amigos, vizinhos e outras pessoas próximas. Os tipos de auxílio incluíam: sustento ou ajuda financeira, apoio emocional, levar para a maternidade e permanecer lá até o nascimento, ajudar a mãe nos primeiros dias com o filho/a, cuidar ou ficar com a criança, abrigar a família, realizar atividades domésticas, e dar apoio em relação ao diagnóstico de infecção pelo HIV/Aids e aos cuidados médicos da mãe e do filho/a. Considerando esses aspectos, todas as mães expressaram que se sentiam seguras e satisfeitas com o tipo de apoio que recebiam: "Eu fiquei muito mal [quando recebeu o diagnóstico]. Dai ela [a mãe] falou assim: 'Ana vamos resolver uma coisa para depois outra. 
Primeiro tu não te preocupa com o teu marido, pra depois tu resolver este teu problema'. Até que eles [a mãe e o irmão] aceitaram a notícia, não tem nenhuma discriminação, nada" (M2). Todavia, quatro mães (M2, M3, M4, M6) acreditavam que o auxílio de algumas pessoas estava, em parte, condicionado ao desconhecimento da infecção pelo HIV/Aids e temiam serem rejeitadas se a doença fosse descoberta: "Eles ficaram todos faceiros [com a gravidez], porque a maioria da minha família não sabe [do HIV]" (M4).

No entanto, em relação ao esposo, a maior parte das participantes (M1, M2, M3, M5) demonstrou algum tipo de insatisfação por sua reação negativa diante da notícia da gravidez e da doença, sua ausência no parto e nos primeiros dias, por ele não se envolver nos cuidados com o filho/a, não ajudar financeiramente ou por provocar brigas: "Ah, o meu marido, como me atrapalhou. Ele é pior que as crianças, ele me dá mais trabalho do que as crianças. Eu dizia que tinha que ir pro médico, ele só me olhava: 'Então vai!'. Nem prá se oferecer pra ficar com os outros dois [filhos], dai eu tinha que levar junto" (M5). As mães relataram ainda ter sofrido ou estar sofrendo algum tipo de restrição em sua rede de apoio, o que se devia a diferentes motivos como morar longe da família, desentendimentos conjugais ou familiares e problemas de saúde. A maior parte das mães (M2, M4, M5, M6) referiu que o diagnóstico de HIV/Aids era responsável pelo seu afastamento voluntário ou não de familiares e/ou pessoas próximas, seja porque estes já sabiam, ou porque não queriam revelá-lo: "O irmão dele falou prá cunhada dele [sobre o HIV] e assim foi [se espalhando a notícia]. E todos se cuidam, se cuidam de mim, porque é um copo ali... Nós nos afastamos porque parece uma doença contagiosa. Contagiosa é, mas não assim, parece que eu tô com uma pereba, uma sarna e que eu já vou te passar, no que tu tocar em mim tu já vai pegar. Então eu achei melhor me afastar" (M4).

Duas mães (M4, M5) tinham enfrentado situações de discriminação relacionadas ao HIV/Aids consigo e/ou com os filhos enquanto as outras evitavam falar sobre a sua doença com familiares e amigos temendo o preconceito e a perda do apoio que recebiam: "O meu guri [outro filho] tinha se cortado, se machucado e a vizinha disse para ela [amiga da participante]: 'Não deixa muito a tua filha perto das crianças da Júlia que eles vão pegar Aids, não sabia'? O que me dá raiva mesmo é o preconceito, excluem as crianças de muita coisa. Festinha, essas coisas, não deixam chegar perto dos meus filhos. Acho que eles pensam que se encostar, pega" (M5). Além disso, quatro mães (M1, M2, M3, M5) referiram não ter como desabafar sobre a doença e sobre os temores com o filho/a, ou porque não haviam revelado isso a ninguém, ou porque os familiares preferiam não comentar o assunto: "A minha família sabe e quer me dar um apoio e ele [o marido] tá sempre na volta e, toca no assunto, ele já muda, troca pra outro, diz que não é pra falar, que é pra tirar da cabeça, que é pra esquecer" (M1).

Os relatos das mães sobre o apoio que recebiam eram predominantemente relacionados a figuras femininas de sua família, como a própria mãe, a sogra, madrinhas do filho/a, irmãs, cunhadas e vizinhas. Todas as mulheres consideravam que tinham a aprovação das pessoas mais próximas no papel de mães, embora tivessem sido questionadas, por pessoas que desconheciam sua doença, sobre o motivo de não amamentarem: "A minha cunhada, a irmã do meu marido, ela não sabe [sobre o HIV]. Dai eu cheguei um dia e ela perguntou por que eu não estava amamentando. Dai eu disse que eu tive infecção urinária e ela viu os exames, viu os remédios e viu que eu tava com infecção. Dai ela disse: 'Secou'? E eu disse: 'Secou'” (M6). A participante primípara manifestou que se sentia destituída do papel de mãe pela conduta das mulheres da família do marido, mantendo com elas uma relação bastante conflituosa.

Como pode ser visto nos relatos acima, todas as mães referiram receber algum tipo de apoio durante a gestação, o parto e os primeiros meses do filho/a, permitindo que elas se dedicassem ao bebê e aos outros filhos. Da mesma forma, todas as mães expressaram medo da discriminação relacionada ao HIV/Aids e buscavam proteger-se, escondendo o diagnóstico de alguns familiares, amigos e vizinhos ou afastando-se de pessoas que expressaram alguma forma de preconceito. Esses achados confirmam que tanto benefícios quanto riscos estão envolvidos na revelação e na ocultação do diagnóstico por parte dessas mães (Sandelowski, Lambe, \& Barroso, 2004). Por sua vez, a nãoamamentação desafiava as mães não somente em relação ao sigilo quanto ao diagnóstico, mas também na avaliação que as pessoas próximas faziam delas como mães. Desse modo, entende-se que diante dos problemas e ameaças que a infecção pelo HIV/Aids impunha à sua rede de apoio e ao seu status materno, as mães buscassem minimizá-los, de várias formas, para receber o auxílio de que precisavam no acolhimento do filho/a.

Considerando conjuntamente os relatos, apareceram algumas particularidades e semelhanças entre as mães que já se sabiam portadoras do HIV/Aids antes da gestação e aquelas que souberam no parto. Somente aquelas mães que sabiam da infecção há mais tempo relataram já terem sofrido concretamente alguma forma de preconceito ou presenciado situações com amigos e outras pessoas próximas que viviam com o HIV/Aids. Mesmo assim, todas as mães tinham medo de sofrer discriminação e do estigma do HIV/Aids, o que influenciava a manutenção ou a busca de apoio, a experiência de ser mãe e as relações familiares, como apontaram outros estudos (Carvalho \& Piccinini, 2006; Ingram \& Hutchinson, 1999b; Knauth, 2001; Nelms, 2005; Sandelowski \& cols., 2004). Dessa forma, os relatos das mães revelaram que o estigma e as crenças equivocadas sobre formas de transmissão do vírus permanecem arraigadas no imaginário social, causando situações de rejeição e exclusão das pessoas portadoras do HIV/Aids.

Em particular, as mães que tiveram o diagnóstico no parto pareciam estar lidando com o impacto do diagnóstico sobre suas relações com o pai do bebê, em particular, e com as figuras de apoio mais próximas. Dessa maneira, uma delas ainda não conseguira revelar o problema para o pai de sua filha e, ao mesmo tempo, as outras referiram modificações e dificuldades na relação com o esposo advindas do diagnóstico e da nova rotina de exames e consultas da família. Apenas a mãe que era primípara referiu dificuldades para lidar com a família do marido, porque sentia que a interferência no cuidado da filha era demasiada. 


\section{Reorganização da identidade}

Este último eixo-temático (Stern, 1997) refere-se à alteração nos investimentos emocionais e atividades da mãe visando o desempenho da função materna. No presente estudo, apenas uma mãe (M2), que não sabia ser portadora do HIV/Aids, havia planejado engravidar. Todavia, as outras mães relataram não estar fazendo uso consistente de nenhum método anticoncepcional na época em que ficaram grávidas. Com a gravidez e o nascimento do filho/a, as mães relataram mudanças na relação com o marido, com a família extensa, com amigos e em função do HIV/Aids. Quanto à relação com o parceiro, a maior parte das mulheres (M1, M2, M3, M5, M6) referiu brigas, vontade de se separar ou dificuldades para conversar, sendo que algumas situações ligavam-se à infecção pelo HIV/Aids: "A gente não sentou pra conversar sobre esse assunto [diagnóstico de HIV], não entrei em detalhe nenhum. Ele fez o exame dele e foi embora então..." (M2). Uma das mães não havia revelado ser portadora do vírus para o esposo na gestação pois temia que ele a abandonasse: "Quando eu descobri que tava grávida eu não quis fazer o tratamento [profilático] porque o meu marido não sabia, eu fiquei com medo de contar para ele e ele acabar me deixando. Daí eu não fiz tratamento por burrice e quando eu fui para ganhar [a filha] ele descobriu, eu falei para ele e ele ficou numa boa" (M6). Outra mãe (M3), que descobriu a doença na maternidade, não contou ao pai de sua filha sobre o vírus porque se separou logo após o parto e não o viu mais.

Além disso, todas as mães reportaram modificações em sua rotina por causa do acompanhamento médico: "Pra mim a única coisa que ficou rotina é estar no hospital. Porque quando não é consulta dela [filha] é a minha, quando não é a minha é a dele [marido], então não faz diferença" (M1). Essas mudanças eram acompanhadas por sentimentos de culpa, de desvalia, de ser diferente dos outros, medo do preconceito, de que o filho estivesse infectado, de morrer ou de ficar doente e não ter condições de criar os filhos: "Só me preocupo de acabar indo [morrer] antes de eles crescerem e já estarem encaminhados na vida deles, só, minha preocupação é essa" (M5). Ao mesmo tempo, os receios das mães eram reforçados por exemplos relacionados à Aids que elas haviam presenciado, por situações trazidas pelo cotidiano, pela mídia e pela desinformação: "[Me sinto] diferente das outras pessoas [se emociona]. Porque todo mundo, parece que nessa hora vem sempre esse assunto [do HIV]. Ficam conversando e aí um lá que não sabe nada de mim puxa o assunto: 'Aí, Aidético...', coisa assim. Eu fico sem responder nada, sem falar, porque tão falando de mim [embora] as pessoas não saibam" (M2).

Quanto ao diagnóstico de HIV/Aids, todas as mulheres, com uma exceção, responsabilizavam o marido pela contaminação. Essas mães buscavam explicações para sua infecção, delegando a culpa à confiança no relacionamento estável ou às relações extraconjugais e uso de drogas do marido: "Ele viaja bastante, eu não sei o que ele faz, eu sei que ele anda cheirando [cocaina], deu umas convulsões nele. Eu sei que ele anda cheirando, vai saber se ele não andou se injetando ou fazendo algo mais, ou se ele não andou com outra mulher? Eu não tenho certeza disso" (M5). Uma mãe (M4) acreditava ter contraído o vírus na adolescência, quando se prostituía, e porque não tinha informações sobre a doença.

Para as três mães que souberam da infecção na maternidade, a descoberta do HIV/Aids era ainda recente e o medo de falecer e de sofrer discriminação e as preocupações com a própria saúde e a do filho/a pareciam mais intensos do que os das demais mães. Essas mães expressaram tentar esquecer ou negar que tinham a doença para conseguir levar seu dia-adia e cuidar dos filhos. Entretanto, com o decorrer do tempo e com o recebimento de novas informações sobre a doença, as mães passaram a ter mais otimismo: "O médico me disse que eu tô magra, mas eu sempre fui magrinha, e ele acha que eu tô magra. Mas eu já tirei da cabeça que não... se eu ficar colocando eu enlouqueço. Eu procuro nem me lembrar muito" (M3). Para as duas mães (M1, M2) que realizaram o teste rápido no trabalho de parto, ser informada da doença naquele momento afetou sua experiência do parto pelo temor de que o filho/a fosse infectado. Entretanto, a primeira reação dessas mães foi de incredulidade e indiferença, o que, na visão delas, permitiu que se mantivessem centradas no nascimento do filho/a: "Quando a doutora me falou [do diagnóstico] a única coisa que tava na minha cabeça é que ela nascesse bem, que ela ia vir bem, que ela ia ser uma enorme de uma guria" (M1).

Por outro lado, as três mães que se sabiam portadoras do HIV/Aids antes da gestação já tinham algumas informações sobre a doença, o que parecia lhes dar um pouco mais de segurança para lidar com a maternidade nessa situação. Ao mesmo tempo, o nascimento do filho/a reacendeu temores relacionados à doença, possibilitou a retomada do próprio tratamento e, em um dos casos, o início do acompanhamento: "De nenhum deles, nem dos guris [outros filhos], nem da outra que faleceu [filha que morreu de Aids], não fiz pré-natal de nenhum. Eu não gostava de médico, agora que eu me vi assim, que eu tô consultando..." (M4). Na época do diagnóstico de HIV/ Aids, essas mães enfatizaram o quanto esse período fora difícil e como suas reações e/ou de familiares haviam sido intensas. Com a notícia da doença durante o pré-natal, uma das mães (M5) abandonou o pré-natal e passou a usar drogas, e outra mãe (M6) rompeu com o pai do seu primeiro filho e sua família queria "matá-lo" porque ele não havia revelado a doença antes. Por fim, a outra participante (M4) soube de sua infecção após a morte de uma filha pequena por Aids e, depois disto, não conseguiu fazer seu teste anti-HIV. Passado o choque da descoberta, essas participantes evidenciaram utilizar uma série de estratégias para lidar com o diagnóstico, como evitar pensamentos negativos e colocar em primeiro plano as preocupações com a criança. Essas mães afirmaram que ser portadora do HIV/Aids não afetava sua maternidade, a não ser por não poderem amamentar, fato apontado por duas participantes (M5, M6), e não influenciaria a relação com os filhos no futuro: "Primeiro eu me senti mal, depois acostumei, eu nem fico botando na minha cabeça que eu tenho HIV, eu levo a vida normal. Eu sei que tenho, mas não fico com aquela coisa na cabeça: eu vou morrer. Quando eles [os filhos] tiverem grandes, que eles souberem o que é, entenderem, quando tiverem com 16, 15 anos [eu conto]. Eu creio que não vai afetar [a relação] com eles" (M6). 
De modo geral, todas as mães demonstraram sentimentos de felicidade, alegria ou completude com a maternidade e afirmaram não se sentirem sobrecarregadas com os cuidados que a chegada do filho/a havia trazido: "Eu não sinto nada pesado, em, nada pra mim, eu cuido dele com todo carinho, com amor, como todos os meus filhos eu cuidei. Pra mim não pesa em nada" (M4). A metade das mães (M1, M3, M5) pretendia retomar logo atividades fora de casa, como fazer cursos e trabalhar, pois precisavam complementar a renda da família.

De acordo com o relato de quase todas as participantes (M1, M2, M4, M5, M6), o HIV/Aids afetou sua vontade de ser mãe uma outra vez e duas delas, inclusive, gostariam de ter feito a laqueadura tubária. O medo de infectar o bebê e a angústia até a confirmação do diagnóstico eram os principais motivos para não quererem mais filhos: " $E u$ queria fazer ligamento, mas ele [o médico] disse que não tem como me dar encaminhamento a não ser que eu tivesse mais um filho. Porque ficar assim naquela expectativa tem ou não tem [o HIV]. É isso que passa na minha cabeça, tem ou não tem" (M1). A maior parte das mães (M1, M2, M4, M6) estava em acompanhamento médico e havia realizado consultas e exames de carga viral e contagem de TCD4 após o parto. No entanto, duas mães (M3, M5) revelaram dificuldades em manter seu acompanhamento, tendo faltado a consultas e exames.

Além desses aspectos, a maternidade mobilizou sentimentos e lembranças nas mães sobre sua infância e/ou conflitos familiares, assim como sobre seus modelos positivos e negativos de parentagem. Todas as entrevistadas avaliaram-se como boas mães por sua dedicação, carinho, cuidado e preocupação com os filhos, sua paciência e por não maltratarem ou baterem neles. Três mães (M2, M3, M4) citaram ter como modelos positivos a própria mãe e outra (M6), a avó materna. Assim, elas identificavam em si características que suas mães haviam demonstrado durante sua infância: "Eu tento passar pros meus filhos o que a minha mãe fez pra mim, eu tento fazer pra eles. A minha mãe sempre foi uma mãe muito presente, a minha mãe nunca foi daquelas mães afastadas, sempre foi presente, sempre foi de se preocupar com a gente. Então com os meus filhos eu também sou assim. Eu acho que eu sou uma mãe muito boa" (M4). A história de vida de quase todas as mães (M1, M2, M3, M4, M6) revelou que suas famílias passaram por grandes dificuldades financeiras quando elas eram pequenas, o que, por vezes, fez com que ficassem afastadas da mãe, devido ao trabalho desta, e assumissem a responsabilidade por irmãos menores.

As participantes lembraram que suas mães thes deixaram aos cuidados de outras pessoas na infância para que pudessem trabalhar e, enquanto para algumas (M2, M3, M4) esse era um exemplo de luta e superação de dificuldades, outras (M1, M6) consideravam que as mães haviam sido muito ausentes: "Muita dificuldade com as crianças, dificuldade porque ela nos cuidou sozinha, nos criou sozinha. Aquela força e vontade de trabalhar pra nos cuidar, assim que eu vejo ela. E agora eu tô morando sozinha, só eu e eles só, tô separada. E eu praticamente, eu sou assim" (M3). Como exemplos negativos do papel de mãe, foram citadas tias, comadres, vizinhas e, uma delas, a própria mãe, em função de aspectos como a falta de cuidado, a complacên- cia, o abandono e o uso de violência física com os filhos. Em particular, três participantes (M1, M5, M6) relataram ter uma relação conflituosa com as mães desde a infância e não as consideravam como modelos a seguir. Uma das participantes considerava que a mãe havia sido omissa e até negligente, o que, para ela, contribuiu para o seu envolvimento com as drogas e para sua saída de casa: "Minha mãe passava mais tempo bebendo do que conversando com nós, não explicou muita coisa, muita coisa que se ela tivesse me explicado eu teria feito muito menos besteira do que eu fiz. A mãe deixava a gente bem mais solta. A gente ficava, se deixasse, a noite toda na rua" (M5).

Examinando em conjunto os relatos, verifica-se que todas as mulheres entrevistadas descobriram-se portadoras do HIV/Aids em uma situação que envolvia a maternidade, seja durante uma gestação, durante um parto ou com a morte de um filho por Aids. O diagnóstico durante momentos tão delicados e envoltos em tantos sentimentos para essas mães gerou, em muitos casos, intensa comoção ou reações impulsivas. Percebe-se o quanto à notícia do diagnóstico foi marcante, especialmente porque envolvia um filho/a. Além disso, os relatos indicaram que a relação com o marido e com os familiares era diretamente afetada pelo HIV/Aids, seja pela sua revelação, pelo segredo que mantinham ou pelos conflitos que havia gerado, corroborando os achados de outros estudos (D'Cruz, 2002; Knauth, 2001; Manoipaboon \& cols., 1998). De modo geral, as dificuldades em revelar o diagnóstico ao pai do bebê, referidas por algumas mães, evidenciaram que este momento requer a atenção especial dos profissionais de saúde e, em alguns casos, inclusive, faz-se necessária ajuda psicológica.

As mudanças e as adaptações psicológicas e familiares necessárias ao nascimento do filho/a foram acompanhadas pela complexidade de uma doença crônica e estigmatizante como o HIV/Aids. Ser mãe no contexto do HIV/Aids exigia lidar com a não-amamentação, com a administração de remédios ao filho/a, com a rotina de consultas e exames, e com o impacto que o estigma provocou ou ameaçava provocar na sua vida familiar e social. Foi possível notar ainda que as mães tentavam justificar a forma de contaminação, eximindo-se da culpa e esforçando-se por se afastar da imagem dos "grupos de risco", aspecto identificado em outros estudos com portadores do HIV/Aids (Parker \& Aggleton, 2003; Seffner, 2001).

Junto ao distanciamento dessa imagem negativa do HIV/ Aids, as mães recorreram aos modelos maternos positivos de que dispunham e/ou procuravam opor-se aos exemplos ruins para manter uma identidade materna forte e que ajudava na superação da infecção. Esses achados são semelhantes aos de Shambley-Ebron e Boyle (2006) que revelaram que as mães portadoras do HIV/Aids apoiavam-se no exemplo de força e coragem de figuras maternas fortes, para lidar com a doença e a maternidade. Como em outras pesquisas, a maternidade permaneceu idealizada para essas mães, sugerindo que a gravidez pode representar uma prova de integridade física e o filho, uma força motivadora para resistir ao vírus (Antle \& cols., 2001; Carvalho \& Piccinini, 2006; Knauth, 1997b; Moura \& Praça, 2006; Nelms, 2005). Pode-se pensar ainda que o acréscimo narcísico e a identificação com o filho, característicos do período de transição para a maternidade 
(Brazelton \& Cramer, 1992; Winnicott, 1956/2000), possibilite a essas mães se sentirem mais fortes frente à doença. Além disso, a busca pela condição de maternidade normal e por uma identidade materna forte pareceu indicar uma estratégia das participantes para driblar a ameaça que o HIV/ Aids representava para a maternidade, como outros autores apontaram (Knauth, 1997a; Nelms, 2005; Sandelowski \& Barroso, 2003). Nesse sentido, os quadros imunológicos estáveis das mães, sem sintomas ou doenças, podem contribuir para a sustentação desse senso materno positivo e de proteção do filho/a. Mesmo assim, elas precisavam elaborar as mudanças advindas com o nascimento do filho/a na presença do vírus, tornando inevitável o tensionamento entre os temores ligados ao HIV e a imagem de si como alguém relativamente saudável, capaz de gerar e manter um filho.

Por fim, algumas particularidades se destacaram entre os relatos das mães que já se sabiam infectadas e aquelas que souberam da infecção no parto. Para as primeiras mães, o maior tempo desde a descoberta e suas experiências com outros filhos parece ter facilitado, em alguns aspectos, a assimilação do diagnóstico ou o enfrentamento da nova situação de maternidade. Já as mães que souberam da infecção no parto lidavam com o choque recente do diagnóstico e com situações inéditas, o que pode ter contribuído para a sensação de mudanças mais drásticas e ameaçadoras em suas vidas.

\section{Considerações Finais}

Os relatos das mães deste estudo evidenciaram o quanto a sua experiência de ser mãe estava permeada pelos desafios e temores ligados à sua condição de portadoras do HIV/ Aids e à possibilidade do filho/a estar infectado. Para as mães que já se sabiam infectadas, esses receios já estavam presentes desde a gestação, enquanto para as demais isso era algo ainda muito recente e difícil de ser assimilado. As restrições financeiras faziam parte da história de vida dessas mães e marcavam não somente o seu contexto atual, mas também a falta de opções e a vulnerabilidade social em que se encontravam desde a infância. Conflitos com o esposo e com a família extensa e o medo de que o preconceito atingisse sua relação com eles no futuro e com pessoas próximas sobrecarregavam ainda mais essas mães. Desse modo, assimilar a doença, o tratamento e os temores quanto à própria saúde e a do filho/a exigia um grande esforço emocional dessas mulheres em um momento em que a maternidade, por si só, já exige uma importante reorganização psicológica e familiar. Com isso, as mães buscavam fortalecer uma identidade positiva e a condição de maternidade normal frente à doença, assegurando uma relação de afeto e proteção do filho/a e garantindo seu desenvolvimento físico e emocional.

$\mathrm{O}$ estudo buscou analisar as semelhanças e particularidades entre os relatos das mães nos quatro eixos temáticos propostos por Stern (1997) sobre a maternidade, que foram ilustrados à luz do contexto do HIV/Aids. As mães demonstraram grande heterogeneidade entre si quanto a suas características pessoais e de sua família, o que enriqueceu as análises. A inclusão de mães que receberam o diagnóstico no parto possibilitou analisar a especificidade que essa situação traz para a vivência de maternidade, aspecto ainda pouco explorado pela literatura. Os depoimentos das mães que realizaram o teste rápido no parto explicitaram a existência de falhas na detecção do vírus HIV/Aids no pré-natal, além de apontar o quanto à notícia da infecção naquela ocasião foi impactante para elas.

O presente estudo utilizou-se somente de entrevistas com um número reduzido de mães, o que limita algumas análises sobre a generalidade desses achados. O uso de observações e testes padronizados em um número maior de mães poderia acrescentar dados relevantes aos achados deste estudo, explorando, por exemplo, o impacto da infecção pelo HIV/ Aids na saúde psicológica dessas mães e as estratégias utilizadas para lidar com a doença. Além disso, o seguimento dessas mães até o diagnóstico final do filho/a forneceria dados sobre a permanência e a adesão dessas mães ao seu próprio tratamento. Questões como a paternidade, o relacionamento conjugal e com a família extensa mereceriam investigações aprofundadas, ampliando a compreensão sobre o impacto da infecção pelo HIV/Aids nessas relações. Cabe ainda destacar que, tendo em vista algumas peculiaridades apresentadas pela única mãe primípara do estudo, considera-se importante que novas investigações examinem como a infecção pelo HIV/ Aids afeta a maternidade dessas mulheres.

Em conjunto com os achados deste estudo, as pesquisas sugeridas poderiam orientar a elaboração de estratégias preventivas e de apoio a mães portadoras do HIV/Aids, visando à promoção da saúde física e mental dessas mães e de seus filhos, assim como a diminuição da condição de vulnerabilidade dessas famílias. Em um contexto de tantos problemas e tensões, em grande parte associados ao HIV/Aids, as mães revelaram intenso sofrimento psíquico e dificuldades em lidar com o diagnóstico, com a manutenção de práticas sexuais seguras, de anticoncepção e de seu acompanhamento de saúde. O relato de algumas mães evidenciou também a falta de informações a respeito de algumas recomendações para profilaxia da transmissão vertical e sobre o prognóstico e tratamento da doença, o que contribuía para aumentar sua ansiedade. Essas evidências podem fornecer subsídios importantes aos profissionais de saúde sobre a realidade vivida por gestantes e recém-mães e as dificuldades que enfrentam nos primeiros meses com seu filho/a na presença do HIV/ Aids. Mais do que isso, espera-se que este estudo desperte o interesse de profissionais e pesquisadores da saúde para a necessidade de intervenções de caráter sistemático que contemplem não só a informação e orientação dessas mulheres, mas também o apoio emocional e o acompanhamento psicológico dessas famílias.

\section{Referências}

Almeida, J. \& Novak, F. (2004). Amamentação: um híbrido natureza-cultura. Jornal de Pediatria (Rio de Janeiro), 80, 119-125.

Antle, B., Wells, L., Goldie, R., DeMatteo, D. \& King, S. (2001). Challenges of parenting for families living with HIV/AIDS. Social Work, 46, 159-169.

Bardin, L. (1977). Análise de conteúdo. Lisboa: Edições 70. 
Bennetts, A., Shaffer, N., Manopaiboon, C., Chaiyakul, P., Siriwasin, W., Mock, P., Klumthanom, K., Sorapipatana S., Yuvasevee, C., Jalanchavanapate, S. \& Clark (1999). Determinants of depression and HIV-related worry among HIV-positive women who have recently given birth, Bangkok, Thailand. Social Science \& Medicine 49, 737- 749.

Brazelton, T. \& Cramer, B. (1992). As primeiras relações. São Paulo: Martins Fontes.

Carvalho, F. \& Piccinini, C. (2006). Maternidade em situação de infecção pelo HIV: um estudo sobre os sentimentos de gestantes. Interação em Psicologia, 10, 345-355.

Coelho, D. \& Motta, M. (2005). A compreensão do mundo vivido pelas gestantes portadoras do vírus da imunodeficiência humana. Revista Gaúcha de Enfermagem, 26, 31-41.

Connor, E., Sperling, R., Gelber, R., Kiselev, P., Scott, G., O’Sullivan, M., VanDyke, R., Bey, M., Shearer, W., Jacobson, R., Jimenez, E., O’Neill, E., Bazin, B., Delfraissy, J., Culnane, M., Coombs, R., Elkins, M., Moye, J., Stratton, P. \& Balsley, J. (1994). Reduction of maternal-infant transmission of Human Immunodeficiency Virus Type 1 with Zidovudine treatment. New England Journal of Medicine, 331, 1173-1180.

D'Auria, J., Christian, B. \& Miles, M. (2006). Being there for my baby: Early responses of HIV-infected mothers with an HIVexposed infant. Journal of Pediatric Health Care, 20, 11-18.

D'Cruz, P. (2002). Engulfing darkness: The impact of HIV/Aids on the family. Families in Society: The Journal of Contemporary Human Services, 83, 416-430.

DeMarco, R., Lynch, M. M. \& Board, R. (2002). Mothers who silence themselves: A concept with clinical implications for women living with HIV/Aids and their children. Journal of Pediatric Nursing, 17, 89-95.

Ethier, K., Ickovics, J., Fernandez, M., Wilson, T., Royce, R. \& Koenig, L. (2002). The Perinatal Guidelines Evaluation Project HIV and Pregnancy Study: Overview and cohort description. Public Health Reports, 117, 137-147.

Ferraz, A. (1998). Tornar-se soropositivo: da perplexidade ao confronto com o incógnito. Em L. Morando \& R. Guimarães (Orgs.), AIDS: olhares plurais - ensaios esparsos sobre a epidemia de HIV/Aids (pp. 111-140). Belo Horizonte: Coordenadoria estadual de DST/Aids de Minas Gerais.

Ickovics, J., Wilson, T., Royce, R., Minkoff, H., Fernandez, M., Fox-Tierney, R. \& Koenig, L., (2002). Prenatal and postpartum zidovudine adherence among pregnant women with HIV: Results of a MEMS substudy from the Perinatal Guidelines Evaluation Project. Journal of Acquired Immune Deficiency Syndromes, 30, 311-315.

Ingram, D. \& Hutchinson, S. (1999a). Defensive mothering in HIVpositive mothers. Qualitative Health Research, 9, 243-258.

Ingram, D. \& Hutchinson, S. (1999b). HIV-positive mothers and stigma. Health Care for Women International, 20, 93-103.

Ingram, D. \& Hutchinson, S. (2000). Double binds and the reproductive and mothering experiences of HIV-positive women. Qualitative Health Research, 10, 117-132.

Knauth, D. (1997a). O vírus procurado, o vírus adquirido: a construção da identidade entre mulheres portadoras do vírus da Aids. Estudo Feministas, 5, 291-302.

Knauth, D. (1997b). A maternidade sob o signo da Aids: um estudo sobre mulheres infectadas. Em A. O. Costa (Org.), Direitos tardios: saúde, sexualidade e reprodução na América Latina (pp. 41-64). São Paulo: Editora 34/FCC.
Knauth, D. (2001). Um problema de família: a percepção de Aids entre mulheres soropositivas. Em O. F. Leal (Org.), Corpo e significado: ensaios de antropologia social (pp. 373-383). Porto Alegre: Editora UFRGS.

Kwalombota, M. (2002). The effect of pregnancy in HIV-infected women. AIDS Care, 14, 431-433.

Laville, C. \& Dione, J. (1999). A construção do saber. Porto Alegre: Artmed.

Lemos, L., Gurgel, R. \& Dal Fabbro A. (2005). Prevalência da infecção por HIV em parturientes de maternidades vinculadas ao SUS. Revista Brasileira de Ginecologia e Obstetrícia, 27, 32-6.

Lindau, S., Jerome, J., Miller, K., Monk, E., Garcia, P. \& Cohen, M. (2006). Mothers on margins: Implications for eradicating perinatal HIV. Social Science \& Medicine, 62, 59-69.

Lopes, R., Alfaya C., Machado, C. \& Piccinini, C. (2005). "No início eu saía com o coração partido...": As primeiras situações de separação mãe-bebê. Revista Brasileira de Crescimento e Desenvolvimento Humano, 15, 26-35.

Manopaiboon, C., Shaffer, N., Clark, L., Bhadrakom, C., Siriwasin, W., Chearskul, S., Suteewan, W., Kaewkungwal, J., Bennetts, A. \& Mastro, T. (1998). Impact of HIV on families of HIV-infected women who have recently given birth, Bangkok, Thailand. Journal of Acquired Immune Deficiency Syndromes, \& Human Retrovirology, 18, 54-63.

Ministério da Saúde (2006a). Boletim Epidemiológico Aids 2006, Ano III, $n^{\circ}$ 1. Brasília: Secretaria de Vigilância em Saúde, Programa Nacional de DST e Aids.

Ministério da Saúde (2006b). Recomendações para a profilaxia da transmissão vertical do HIV e terapia anti-retroviral em gestantes. Brasília: Secretaria de Vigilância em Saúde, Programa Nacional de DST e Aids.

Moreno, C., Rea, M. \& Filipe, E. (2006). Mães HIV positivo e a não-amamentação. Revista Brasileira de Saúde MaternoInfantil, 6, 199-208.

Moura, E. \& Praça, N. (2006). Transmissão vertical do HIV: expectativas e ações da gestante soropositiva. Revista LatinoAmericana de Enfermagem, 14, 405-413.

Nelms, T. (2005). Burden: The phenomenon of the mothering with HIV. Journal of the Association of Nurses in Aids Care, 16, 3-13.

Paiva, V., Lima, T., Santos, N., Ventura-Filipe, E. \& Segurado, A. (2002). Sem direito de amar? A vontade de ter filhos entre homens e mulheres vivendo com HIV. Psicologia USP, 13, 105-133.

Parker, R. \& Aggleton, P. (2003). HIV and AIDS-related stigma and discrimination: A conceptual framework and implications for action. Social Science \& Medicine, 57, 13-24.

Programa Conjunto de las Naciones Unidas sobre VIH/SIDA ONUSIDA (2006). Informe sobre la epidemia mundial de SIDA 2006. Retirado em 08/06/06 de http://www.unAIDS.org/en/ HIV_data/2006globalreport/2006_GR_es.asp.

Sandelowski, M. \& Barroso, J. (2003). Motherhood in the context of maternal HIV infection. Research in Nursing \& Health, 26, 470-482.

Sandelowski, M., Lambe, C. \& Barroso, J. (2004). Stigma in HIV-positive women. Journal of Nursing Scholarship, 36, 122-128.

Santos, N., Buchalla, C., Fillipe, E., Bugamelli, L., Garcia, S. \& Paiva, V. (2002). Mulheres HIV positivas, sexualidade e reprodução. Revista de Saúde Pública, 36, 12-23. 
Seffner, F. (2001). AIDS, estigma e corpo. Em O. F. Leal (Org.), Corpo e significado: ensaios de antropologia social (pp. 385408). Porto Alegre: Editora UFRGS.

Serruya, S., Cecatti, J. \& Lago, T. (2004). O programa de humanização no pré-natal e nascimento do Ministério da Saúde no Brasil: resultados iniciais. Cadernos de Saúde Pública, 20, 1281-1289.

Shambley-Ebron, D. \& Boyle, J. (2006). In our grandmother's footsteps: Perceptions of being strong in African American women with HIV/AIDS. Advances in Nursing Science, 29, 195-206.

Souza Jr., P., Szwarcwald, C., Barbosa Jr, A., Carvalho, M. \& Castilho, E. (2004). Infecção pelo HIV durante a gestação: estudo sentinela-parturiente. Revista de Saúde Pública, 38, 764-772.

Stern, D. (1997). A constelação da maternidade. Porto Alegre: Artes Médicas.

Stevens, P. \& Doerr, B. (1997). Trauma of discovery: Women's narratives of being informed they are HIV-infected. AIDS Care, 9, 523-538.

Szejer, M. \& Stewart, R. (1997). Nove meses na vida da mulher: uma abordagem psicanalitica da gravidez e do nascimento. São Paulo: Casa do Psicólogo.

Szwarcwald, C. \& Castilho, E. (2000). Estimativa do número de pessoas de 15 a 49 anos infectadas pelo HIV, Brasil, 1998. Cadernos de Saúde Pública, 16 (Supl.1), 135-141.
Szwarcwald, C. \& Souza Jr, P. (2006). Estimativa de prevalência de HIV na população brasileira de 15 a 49 anos, 2004. Boletim Epidemiológico Aids 2006, Ano III, $n^{\circ} 1$. Brasília: Ministério da Saúde, Secretaria de Vigilância em Saúde, Programa Nacional de DST e Aids.

Tompkins, T., Henker, B., Whalen, C., Axelrod J. \& Comer, L. (1999). Motherhood in the context of HIV infection: Reading between the numbers. Cultural Diversity and Ethnic Minority Psychology, 5, 197-208.

Van Loon, R. (2000). Redefining motherhood: Adaptation to role change for women with AIDS. Families in Society: Journal of Contemporary Human Services, 81, 152-161.

Vermelho, L., Barbosa, R. \& Nogueira, S. (1999). Mulheres com Aids: desvendando histórias de risco. Cadernos de Saúde Pública, 15, 369-379.

Winnicott, D. (2000). Preocupação maternal primária. (D. Bofomoletz, Trad.). Em D. Winnicott (Org.), Da pediatria à psicanálise: Obras escolhidas (pp. 399-405). Rio de Janeiro: Imago. (Trabalho original publicado em 1956)

Recebido em 06.08.2007

Primeira decisão editorial em 17.06.2008

Versão final em 30.06.2008

Aceito em 15.10.2008 